\title{
Fire Safety Assessments in Petrochemical Plants
}

\author{
YOICHI UEHARA \\ Yokohama National University \\ Faculty of Engineering, Department of Safety Engineering \\ 156 Tokiwadai, Hodogaya-ku, Yokohama 240, Japan
}

\section{ABSTRACT}

Catastrophes in petrochemical plants dealing with a large amount of flammable materials are most liable to be caused due to destruction or loss of functions of equipment or installations accompanied by great earthquake. In this paper, two safety assessment methods to prevent such disasters are presented. One is to determine, by beeping potential danger of fires and disastrous explosions of facilities where flammable materials are dealt with in mind, the degree of the antiseismic design of facility in accordance with the extent of hypothetical disaster (Importance Classification). Another is to make comparison with the societal acceptance level by keeping a disaster scenario at the time when a plant encounters a great earthquake in mind and by investigating the events accompanying the scenario with the attachment of a probability. Furthermore, by inquiring if there is any influence outside the premises even though there occur fires and disastrous explosions at the level, the safety of the facilities is evaluated.

KEYWORDS: Fire risk assessment, Importance of facility, Antiseismic design, Petrochemical plant, Potential hazara index

\section{INTRODUCTION}

Because large amounts of flammable gases and liquids are daily handled and routinely stored and because of the chemical reactions involved in the manufacturing processes, petrochemical plants are believed to be continuously exposed to the risk of fires and explosion accidents. Although the disposition of equipment to minimize the risk of disaster caused by the fires and explosion accidents, the best preventive method is to remove the causes of accidents. In other words, prevention is the best cure. To realize this objective Fire Safety Assessment methods for the prevention of fires and explosion accidents are urgently required. Methods of assessment regarding the safety of petrochemical plants have been developed and have been in practical use for many years, and the benefits are now being realized.

For such a safety assessment, the evaluation of the danger of the chemical substances currently in use is first required. Data sheets for 
substances and/or risk classification of substances by the National Fire Protection Association of America (NFPA) are of great help in this. [1] In addition to a program to minimize the risks of such substances, a hazard assessment project based on a fire/explosion index of plants handing hazardous materials has been developed by the Dow Chemical Company. Various kinds of improvement have been made to this method, which is now available through the American Institute of Chernical Engineers (AIChE).[2] At present, the 6th version is in use by many people. When a plant starts its operation, its operability is greatly concerned with the prevention of accidents. Hazard analysis and Operability Study are most widely used for assessing risks. [3] By regarding accidents as peak events; FTA (Fault Tree Analysis) is used to pursue their causes. Concurrently with this, ETA (Event Tree Analysis) is available to assess the safety of plants and FMEA and/or FMECA (Failure Mode Effect (Criticality) Analysis) may aiso be useful.[4]

In this paper, the two methous of fire safety assessment which were developed in Japan are discussed, that is, one is a method of evaluating the potential danger concerning fires and explosion accidents in plants and for the antiseismic design (Importance Classification) and the other is the assessment that is largely based on the consideration of scenarios of accidents for plants which have already been built.

\section{IMPORTANCE CLASSIFICATION [5]}

\section{Scope}

In Japan, we have many earthquakes, not infrequently these are severe. At the Great Kanto Earthquake in 1923, no less than 100 thousand people died from the fires which broke out afterwards.

Should petrochemical plants be destroyed by a great earthquake, a catastrophe is naturally to be expected. This is particularly so in Japan where usable land is very limited. Towns and petrochemical complexes are unavoidably located so closely to each other that the results of disasters would be very grave. The most effective method to prevent the destruction is to endow the facilities with antiseismic performance. Strict earthquake- resistance should be provided for the facilities which are liable to suffer most from the influence of disasters, while lesser resistance need be provided for the ones with less influence on safety in case of serious destruction. That is to say, the antiseismic design should be adjusted in accordance with the importance of the facilities to be protected.

We start with the supposition that fires and explosion accidents will occur, together with leakage and diffusion of toxic gases. It is assumed that the facilities are completely unprotected and that they have no earthquake-resistance. In other words, the supposition is made that the greatest degree of destruction will occur. The object of the importance classification is to actualiy achieve, as a preventive measure, antiseismic design to withstand the effects of such disasters. Our discussion in this paper is to be restricted only to fires and explosion accidents. 
The author is not certain whether the term "Importance" is an adem quate one for this discussion. He is also doubtful if the common expression of potential hazard classification is quite proper in describing his intention. A precise English equivalent for his Japanese term has yet to be coined. Anyway the term importance classification is used to classify the facilities in accordance with their degree of risk which in turn enables the potential danger of the system to be assessed. By this classification, the installation of safety measures for the prevention of disaster is considered together with antiseismic design. Assumed disasters dealt with in this paper are those in which fires and explosion accidents occur in an entirely unprotected situation, accompanied by leakage and/or diffusion of poisonous gases into an entirely unprotected area and where there is no consideration for antiseismic provision. In short, an assumption is made, that the greatest foreseeable disaster will result. It is clearly important both to incorporate antiseismic design and disaster prevention measures. However, in this paper fires and explosion accidents are only dealt with.

Facilities are classified in accordance with the importance. Also in accoraance with the said classification, the degree of antiseismic design and earthquake resistant construction are made. The importance is furthermore classified, in accordance with how the degree of importance is, into the three categories shown below, In case of petrochemical complexes, sub-classification IA can be intended to be provided, especially taking account of its importance in addition to the Importance $I$.

Importance I : The damage and the loss of functions are comprehensive enough to inflict a lot of damage upon third person's Iife and property outside of premises.

Importance II : The damage and the loss of functions are comprehensive enough to inflict some damage upon third person's life and property outside the premises.

Importance III: In possession of useful earthquake resistance.

\section{Selection of Disaster Mode}

Dangerous materials studied:Flammable gases and liquids were selected for the assessment since they have caused serious fire/explosion accidents. The actual disasters may extend to other facilities due to the spread of fire and propagation of explosion. However, in this paper the potential hazard was evaluated only for a single facility. This is because the spreading effect is prevented from being referred to its complication.

Selection of disaster modes:There are several kinds of disaster depending on the varieties of dangerous materials. Among them, risks arising from pool fire (tank fires, flooded petroleum fire and vapour cloud explosions of liquefied petroleum gas have been taken into consideration.

The effects of the different kinds of hazard have been evaluated by considering the physical influence on a person exposed to varying intensities of fire and explosions. The measurement of the intensity of the peak explosion pressure from the vapour cloud explosion, radiation 
heat from the pool fire or fire ball has been made. The assessment of potential hazard was performed depending upon these factors.

Critical intensity of danger:The critical intensities were classified into four levels in accordance with the seriousness of their effects.

Level 1 : Intensity at which instantaneous death occurs.

Level 2 : Intensity at which serious effects are exerted on human body within a short time.

Level 3 : Intensity at which mild influence is exerted on human body for a short time

Level 4 : Intensity which engenders fear, or disturbance develops on prolonged exposure.

As described above, these levels were determined in accordance with the effect exerted to the human body. the equivalence of effects was estimated from a survey of the literature. The critical intensities of danger in the fire and explosion mode are shown in TABLE 1.

TABLE 1 The critical intensities in fire and explosion mode

\begin{tabular}{|c|c|c|c|}
\hline $\begin{array}{l}\text { Kind of hazard } \\
\text { Influence level }\end{array}$ & $\begin{array}{c}\text { Explosion } \\
\mathrm{p} \\
\mathrm{kPa} \\
\left(\mathrm{kgf} / \mathrm{cm}^{2}\right)\end{array}$ & $\begin{array}{c}\text { Pool fire } \\
\text { E } \\
\mathrm{kW} / \mathrm{m}^{2} \\
\left(\mathrm{kcal} / \mathrm{m}^{2} \mathrm{~h}\right)\end{array}$ & $\begin{array}{c}\text { Fire ball } \\
\text { E } \\
\mathrm{kW} / \mathrm{m}^{2} \\
\left(\mathrm{kcal} / \mathrm{cm}^{2} \mathrm{~h}\right)\end{array}$ \\
\hline 1 & $\begin{array}{r}294.21 \\
(3.0)\end{array}$ & $\begin{array}{l}11.62 \\
(10,000)\end{array}$ & $\begin{array}{c}69.72 \\
(60,000)\end{array}$ \\
\hline 2 & $\begin{array}{l}98.07 \\
(1.0)\end{array}$ & $\begin{array}{c}8.13 \\
(7,000)\end{array}$ & $\begin{array}{c}46.48 \\
(40,000)\end{array}$ \\
\hline 3 & $\begin{array}{l}29.42 \\
(0.3)\end{array}$ & $\begin{array}{c}4.65 \\
(4,000)\end{array}$ & $\begin{array}{c}11.62 \\
(10,000)\end{array}$ \\
\hline 4 & $\begin{array}{r}9.81 \\
(0.1)\end{array}$ & - & - \\
\hline
\end{tabular}

Calculation of critical distance of danger and hypothetical affectedarea

Explosion hazard

Calculation of critical distance of danger: The relation between explosion pressure and distance in the case of detonation of TNT explosive is given by equation (1).

$\lambda=\mathrm{R} / \mathrm{WTNT}_{\mathrm{TNT}} 1 / 3$,

where $\lambda$ is the reduced distance (unit: $\mathrm{m} / \mathrm{kg}^{1 / 3}$ ) and is related to peak pressure as shown in Table 1 , and $R$ the distance from the centre of the explosion. This equation, however, cannot be directly applied to gases 
or liquefied gases. Especially liquefied gases in large in quantity which are not completely gasified instantaneously and the whole quantity does not necessarily contribute to the explosion. Moreover, explosions do not always take place, as with the case of the detonation of TNT. Taking into account these facts, reduced TNT quantity, WTNT, is given by the following equation if the liquefied gas quantity is represented by wor

$W_{\mathrm{TNT}}=\mathrm{WO}_{\mathrm{T}} \mathrm{f} \cdot \psi \cdot \gamma \cdot Q / 4,184$,

where $f$ is the rate of gasification, $\psi$ the explosion coefficient, $\gamma$ the detonation coefficient, $Q$ the combustion heat of liquefied gas and dominator $4,184 \mathrm{~kJ} / \mathrm{kg}$. (1000 kcal/kg) the combustion heat of $1 \mathrm{~kg}$ of $\mathrm{TNT}$. Since it has been shown by experience that $f$ takes the value of approximately 0.1 and $\gamma$ approximately 0.064 , these values are introduced into equation (2) after the arrangement of equation (1). Thus, the critical distance of danger $\mathrm{X}_{\mathrm{C}}$ for each $\lambda$ is obtained in the following equation,

$X_{C}=0.04 \cdot \lambda(\mathrm{kWO})^{1 / 3}$,

where $\mathrm{k}$ is a function of the types and conditions of gases, and other parameters are the same as those in the equation (2).

The relation between reduced distance and peak pressure for each influence level given in TABLE 2.

TABLE 2 The relation between reduced distance and peak pressure

\begin{tabular}{ccc}
\hline Influence level & $\begin{array}{c}\text { Peak pressure } \\
(\mathrm{kPa})\end{array}$ & $\begin{array}{c}\text { Reduced distance } \\
\left(\mathrm{m} / \mathrm{kg}^{1 / 3}\right)\end{array}$ \\
\hline 1 & 294.21 & 1.90 \\
2 & 98.07 & 3.20 \\
3 & 29.42 & 6.40 \\
4 & 9.81 & 13.8 \\
\hline
\end{tabular}

Hypothetical affected-area: If the critical distance of danger is represented by $X_{C}$, the hypothetical affected area, $A$, corresponding to each level of $\lambda$ is obtained from,

$\mathrm{A}=\pi \cdot \mathrm{X}_{\mathrm{C}}^{2} \times 10^{-6}\left(\mathrm{~km}^{2}\right)$.

Pool fire:Pool fires may be classified into tank fires caused by the destruction of the top of the tank and a subsequent fire of flooded oil in a dike or fires on the surface of water. This paper deals with the latter case because it is generally more serious.

Radiation heat $E$ from the $F$ lame is calculated by the equation,

$E=\sigma \cdot \varepsilon \cdot T^{4} \phi$, 
where $\sigma$ is the Stefan-Boltzman constant, $\varepsilon$ the emissivity ( 1 for perfect black body), T the temperature of the flame and $\phi$ the configuration factor determined by the shape and distance from the flame to the heat receiving surface.

If $\sigma \cdot \varepsilon \cdot T^{4}$ is considered collectively as irradiance $R_{f}$, equation (5) is simplified as shown below,

$E=R_{f} \cdot \phi$.

$R_{f}$ has values specific to particular fuels and can be obtained by measurement.

Since fires in liquid fuels have almost cylindrical flames, the configuration factor $\phi$ can be obtained in the following equation, where the radius, height and distance from the flame centre to the heat receiving surface are represented by $R, H$ and $L$, respectively.

$\phi=\frac{1}{\pi Y} \tan ^{-1}\left(\frac{X}{\sqrt{Y^{2}-1}}\right)+\frac{X}{\pi}\left(\frac{(A-2 Y)}{Y \sqrt{A B}} \cdot \tan ^{-1}\left(\sqrt{\frac{A(Y-1)}{B(Y+1)}}\right)-\frac{1}{Y} \tan ^{-1}\left(\sqrt{\frac{(Y-1)}{(Y+1)}}\right)\right)$

where $X=H / R, Y=L / H, A=(1+Y)^{2}+X^{2}$ and $B=(1-Y)^{2}+X^{2}$.

Thus, radiation heat from a pool fire can be obtained. However, since the equation is too complicated to calculate, critical distance of danger is determined in accordance with the linear approximation of equations (6) and (7).

For this purpose, the value of $D$ is determined at first from equation (8).

If D) 6 , each level of critical distance of danger $x_{C}$ can be $a b-$ tained from equation $(9)$.

$D=0.5925 /\left(\left(E / R_{f}\right)+0.04805\right)$

$X_{C}=D \cdot r$.

If $6<D<10, X_{C}$ is calculated in the following equation.

$X_{c}=\left(1.485 R_{f} / E\right)^{0.531} \cdot r$.

Here, $r$ is the equivalent radius of the pool.

Hypothetical affected-area

Hypothetical affected-area $A$ can be calculated, in the same way as the case of explosion using equation (4),

$A=\pi \cdot x_{C} \times 10^{-6}\left(\mathrm{~km}^{2}\right)$.

Fire ball:

Calculation of critical distance of danger: The relation between the size 
of fire ball and the quantity of flammable substance has already been established by Gayle et al.[6]. Since a fire ball can be regarded as a circle from the viewpoint of heat emission, the configuration factor $f$ at the time of maximum heat can be obtained in the following equation,

$\phi=R^{2} / L^{2}$,

where $R$ is the radius of the circle and $t$ the distance from the centre of the fire ball to the heat receiving surface. If $L$ is regarded as nearly equal to critical distance of danger $x_{C}$, the distance in question can be obtained in the following equation as a function of $E$ in each level combined with Gayle's equation,

$\mathrm{X}_{\mathrm{C}}=1.190 \times 10^{4}[((32 \mathrm{~F} / \mathrm{M})+1) \mathrm{f} \cdot \mathrm{w}]^{0.325}\left(1 / \mathrm{E}^{0.5}\right)$,

where $F$ is the mole numbers of oxygen required for the complete combus tion of 1 mole of the fuel, $M$ the molecular weight of fuel, $f$ the evaporation rate of liquefied fuel and $w$ the fuel quantity in which the yield should be considered in accordance with the same reason on the case of explosion.

Hypothetical affected-area: Hypothetical affected-areas can be calculated in the same manner as the previous cases.

\section{Consideration of Regional Population}

Since the final evaluation of this chapter is based on the population, we must consider the population in the hypothetical affected-area who might suffer from the hazards of dangerous materials. There are two ways to evaluate the said density; one is to adopt a detailed census of the population of the area, and the other is to use the typical population which is assigned according to zones. The land has been zoned in Japan in accordance with the City Planning Law and the Building Standards Law.

As it is troublesome to take a detailed census and such areas are clearly definite, the latter method was mainly employed in this study.

TABLE 3 The relation of zone and population factor

\begin{tabular}{|c|c|c|c|c|c|c|}
\hline $\begin{array}{l}\text { Areas in the } \\
\text { hypothetical } \\
\text { affected-area }\end{array}$ & Premises & $\begin{array}{l}\text { Restricted } \\
\text { industrial } \\
\text { area }\end{array}$ & $\begin{array}{l}\text { Industri- } \\
\text { al area }\end{array}$ & $\begin{array}{l}\text { Residental, } \\
\text { commercial, } \\
\text { semi-indus- } \\
\text { trial areas }\end{array}$ & $\begin{array}{l}\text { Forests, } \\
\text { fields, } \\
\text { greens }\end{array}$ & $\begin{array}{l}\text { Sea, } \\
\text { rivers, } \\
\text { eto. }\end{array}$ \\
\hline $\begin{array}{l}\text { Population } \\
\text { factor }\end{array}$ & 5 & 10 & 20 & 100 & 5 & 0 \\
\hline
\end{tabular}


The regional factors proposed here on the basis of this concept are shown in TABLE 3 . The figures in this table were indexed by dividing the population per $\mathrm{km}^{2}$ by 100 . Accordingly, if these values are not in agreement with actual situations, it is easy to adjust them to practical population densities.

\section{Consideration of Difference in the Intensity of Disaster}

As has been mentioned in the preceding chapters, hazard can be evaluated on the basis of the population contained in the hypothetical affected-area, but the intensity of types of dangerous effects actually exerted on the human body vary with the ones shown by the influence levels. Accordingly, these difference must also be considered. These effects were expressed by influence factors decreasing from 1 for influence level 1 to 0.03 for level 4 as shown in ThBLE 4 .

TABLE 4 The relation between influence level and influence factor

\begin{tabular}{lllll}
\hline Influence level & 1 & 2 & 3 & 4 \\
\hline Influence factor & 1.0 & 0.3 & 0.1 & 0.03 \\
\hline
\end{tabular}

Oyeral1 Evaluation of Hazards and An Exampie of Calculation

The overall evaluation of the potential hazards of facilities for flammable materials would be possible in accordance with the following procedure.

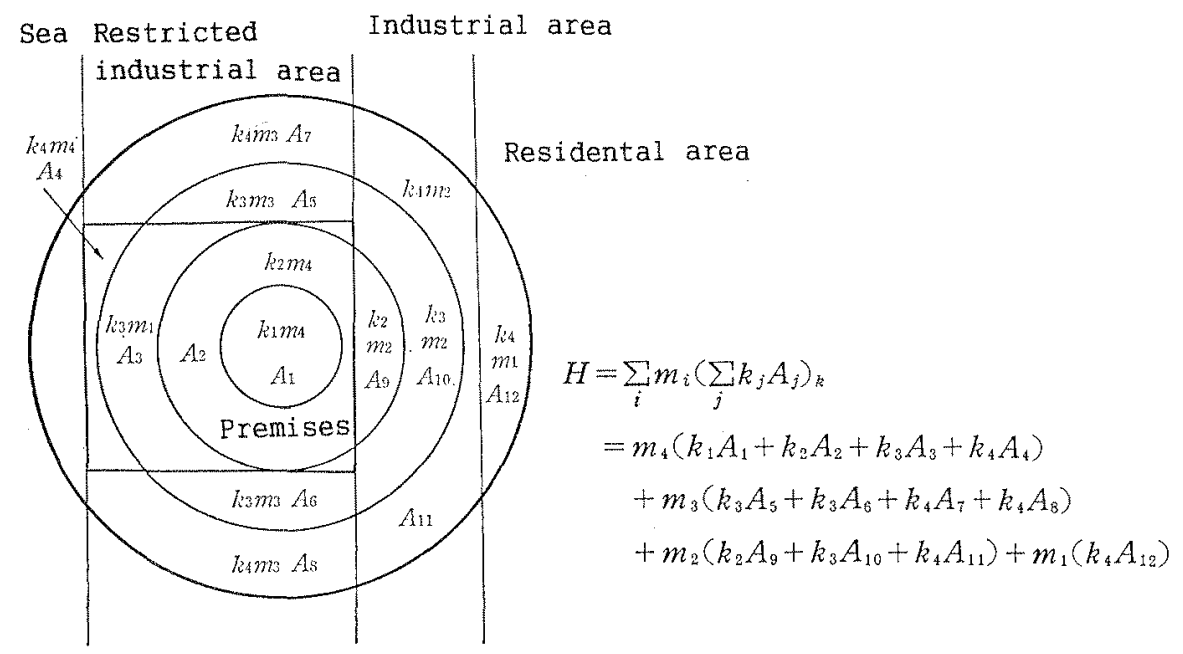

FIGURE 1 Calculation model of potential hazard index 
(1) The disaster modes fitted to the actual circumstance of the facility are selected.

(2) Critical dangerous distance according to each influence level is calculated for each disaster mode and hypothetical affected area at each level is calculated from the distance,

(3) Overall potential hazard index, $\mathrm{H}$, is calculated in the following equation,

$H=\sum_{i} \mathrm{~m}_{i}\left(\sum \mathrm{k}_{j} \mathbb{A}_{j}\right)_{i}$

where $\mathrm{m}_{i}$ is the population factor shown in TABLE $3, \mathrm{~A}_{j}$ the area $\left(\mathrm{km}^{2}\right)$ contained in each influence level given in TABLE 1 and $k_{j}$ the influence factor shown in TABLE 4. The importance of the facility is evaluated on the basis of the potential hazard index.

An example of calculation procedure is shown in FIGURE 1.

\section{SAFETY ASSESSMENT $[6-10]$}

\section{Scope}

Safety assessments for plants existing is a process to check whether, or not, there is an influence on the urban development surrounding the facilities at risk. This is based upon a scenario of the envisaged disaster and its extent, which is fundamental to the development of a safety plan for the people living in the surrounding area. This will incorporate various kinds of disaster prevention countermeasures, for localizing the disaster. The contents of the safety assessment are comprised of an investigation of the extent of the disaster and the calculation of the areas likely to be affected by it. The assessment will also address problems regarding disaster prevention and the establishment of preventive countermeasures.

Event Tree (ET) analysis is availabie as one of the methods to determine the size of disaster by investigating the extent of significant damage for the disasters under discussion. ET analysis is a method of sketching a developmental process upon a tree, when initiating events such as abnormality or disorder of the equipment, installations, etc. are identified. With this method, success or failure of the preventive countermeasure in the individual steps is evaluated.

This allows the process from the inception of the disaster to the maximum area of its effects be seen in terms of time, and comparison to other disasters.

\section{Methodology}

When disasters are investigated using ET analysis, it is necessary to thoroughiy consider the accumulated experience of past disasters. At the same time, it is necessary to consider the action of the various kinds of safety equipment used and disaster-prevention installations. Increasing the scale of disasters by means of the ET analysis can be 
continued indefinitely even if their probability becomes small. Thus it is difficult to determine where the analysis should be discontinued. To actually determine this matter, consideration of the degree of societal acceptability of risk is important.

\section{Determination of the Probability}

Determination of the probabilities of the occurrence of accidental events or protective success in the ET analysis is made not only by minutely investigating and analyzing past accidents but also by considering the performance of the disaster prevention measures employed at the time. However sufficient information regarding these probabilities may not necessarily be available. Accordingly this may compel reliance on current technological experience. However the results obtained should not be markedly different from the above.

\section{A Target of Safety Level-Societally Accepted Safety Level}

A societally acceptable safety level is not a concept used in Japan, because accidents, it is believed, should never be allowed to occur. However, accidents and disasters are frequent. When the occurrence of accidents in Japan involving fires as the main feature is examined, the following results are obtained.

Frequency probability: $10^{-4}-10^{-5}$ (per year, per facility) Death rate: $\quad 10^{-5}$ (per year, per facility)

These values are believed to be the safety levels tacitiy accepted by society. Target safety levels are raised one digit to $10^{-6}$ (per year. per facility). If residences and offices outside the plant are likely to be affected, a reassessment of the safety of the facility and the preventive systems must be made.

\section{Evaluation of the Danger in Accordance with the Influential Range}

FIGURE 2 illustrates the ET analysis of a large petroleum tank being damaged by a severe earthquake with fire breaking out in an oil spillage. In the figure, figures in the parentheses indicate the probabilities of the events shown above being generated, and figures out of the parentheses denote the probabilities ranging from the triggering events to the ones shown above. Even with the same events, larger probabilities are given priority in case of their process or probabilities being different. On this occasion, the analysis is based on the premise, of past experience, that a severe earthquake happens at least once every hundred years. Although it is possible to suppose that in an extreme case a disaster may lead, for example, to outbreak of fire in Tokyo Bay, fires on dikes should be considered as a problem only if the level surpasses the societally accepted safety level by one digit as referred to above. From this, it is concluded that only the limited influential range should be investigated.

By conducting the ET analysis and by considering severity probabilities as high as those referred to in the previous section, calculation of the range of influence of extensive disasters is made with the aid of the same method used in the importance classification. It 
follows that the area affected by the critical effects of the disaster will vary in accordance with the natural disaster. Finally whether measured, or not, the possible effects on the third persons lives and properties on offices are important. As far as the disasters are likely to be restricted to the plant, it is considered safe. If, however, the effects of the disaster are likely to extend to the outside, increasing the safety of the facilities or renovating existing protective equipment is required.

\section{CONCLUSIONS}

In this paper, two safety assessment methods for petrochemical plant were described. One of them deals with a evaluating method in which the hypothetical disasters are considered and the potential hazards for the facilities of flammable materials are evaluated on the basis of the population who might be suffering from the disasters under the unprotected situation.

This method is useful for the quantitative evaluation of potential hazards of facilities dealing with a large anount of flammable materials and it is also useful for the determination of the degree of antiseismic design. The consideration gives to the selection of sites and layout for a facility in accordance with this paper would enhance safety to a great extent.

Another fire safety assessment is made based upon various suppositions. With respect to the probabilities of the individual events, there is a reliance on people manning the facility who have substantial experience. It can hardly be said that a quantitative treatment is utilized in making safety assessments. In future, it will be a duty for us to seek adequate quantitative data in this field.

On the other hand, although scenarios may be almost complete for a single facility, none of the countermeasures may have been taken with respect to the occurrence of a disaster in multiple facilities or the extent of the effects from a disaster in multiple facilities. This might be due to the scarcity of the examples of disasters. Thus it is very important for our studies to evolve in this direction.

These works have been originated in the committee for the evaluation of potential hazards of facilities of flammable materials which was organized in Ministry of International Trade and Industry and The High Pressure Gas Safety Institute (KHK). The institute for Fire Safety and Disaster Preparedness (Shobo Kagaku Sogo Centre )has contributed the improvement of ET analysis. It is a pleasant duty for the author of this paper to thank all the members who participated in these works. All the approximation equations for the critical distance of danger have been derived by Mr. Y. Tonogai, to whom the author wishes to express his deep gratitude.

Despite so many of distinguished researchers' considerate and valuable assistance, the author is afraid that the paper will still not be liberated from some defects, for which he is solely responsible. 


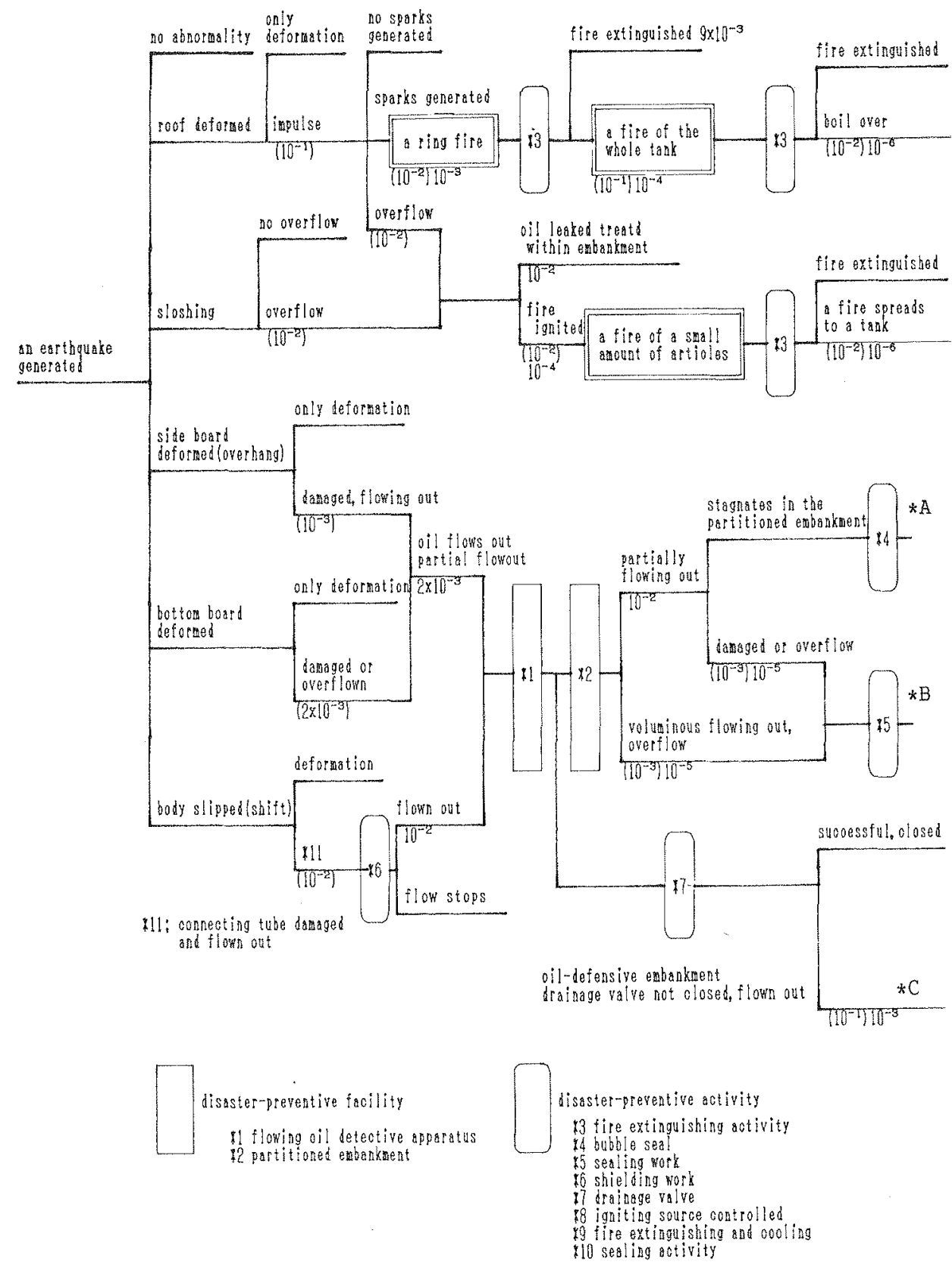




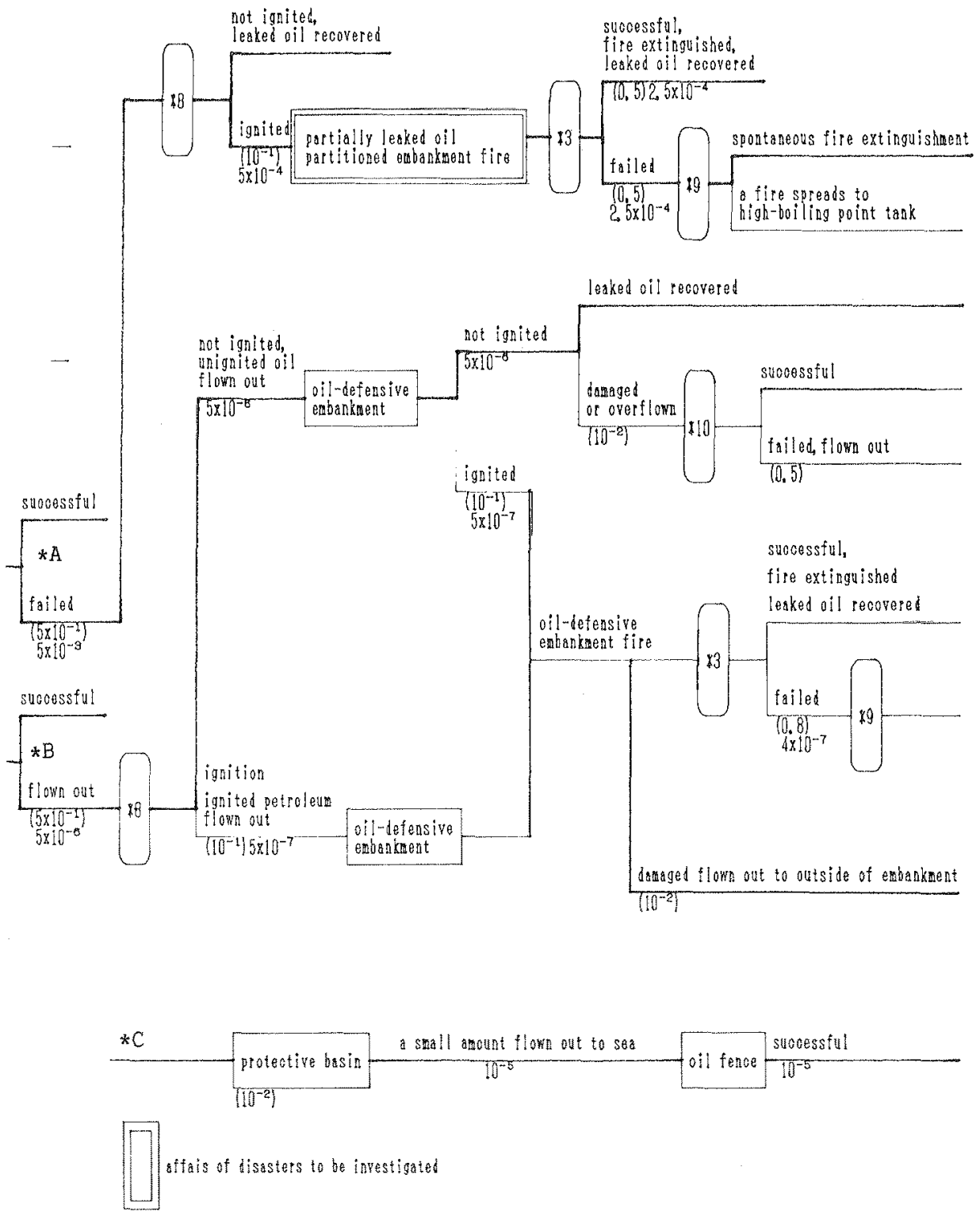

FIGURE 2 Disaster magnified ETA of crude oil tanks (floating group type) in case of an earthquake being in progress, (Units are all 1/earthquake base). 


\section{REFERENCES}

[1]"National Fire Protection Association, Fire Protection Guide on Hazardous Materials, 9th ed., (1986).

[2] American Institute of Chemical Engineers (AIChE), Dow's Fire and Explosion Index, Hazard Classification Guide, 6th ed. (1987).

[3] Kletz, T.A.,Hazop and Hazan-Notes on the Identification and Assesment of Hazards, Institution of Chemical Engineers, (1983).

[4] Lees, Frank P., Loss Prevention in the Chemical Process Industries, Vol. I and II, Butterworth, (1983).

[5] Uehara,Y.. A Rating Method of Potential Hazards of Dangerous Goods, Proceedings of 6th International Symposium of the Transport of Dangerous Goods by Sea and Inland Waterways, p261 (1980).

[6] Health and Safety Executive, Canvey:An Investigation of Potential Hazards from Operations in the Canvey Island/Thurrock Area, (1978).

[7] Setoya,H., Safety Assessment for An Existing Petrochemical Complex, J. Japan Society for Safety Engineering, 16(2), 77 (1977).

[8] MITI, Report on Safety Assessment for A Existing Petrochemical Complex at Great Earthquake (1978).

[9] Uehara, Y. Hazard Evaluation and Safety Assessment of Petrochemical Complex, Chemical Engineering, 28(9), 31 (1983).

[10] Institution for Fire Safety and Disaster Preparedness, Report on Safely Assessment and Disaster Prevention for the Road through the Petrochemical Complex, (1990). 